fluenzal pneumonia, coccidiomycosis, $Q$-fever and psittacosis. An especially long and detailed section, illustrated by X-ray photographs, deals with primary atypical pneumonia. Another article is devoted to the condition known to some as infiltration of Hegglen or pneumonia associated with a positive Wassermann reaction. Treatment of the pneumonias with penicillin and sulphonamides is the subject of another article, and there are abstracts from literature dealing with other aspects of the study of inflam. mation of the lungs. A short section records two immunological laboratory procedures. A bibliographical section consists entirely of the contents of the British Medical Journal during the months January to April 1946.

The next issue of this journal will be devoted to cecent progress in the treatment of disease with penicillin, and will contain articles by Sir Alexander Fleming and Sir Howard Florey, the translation of these two articles having been aided by the British Council. The editors offer a special word of thanks to the British Council and to the president of the Medical Section of American Relief in Italy for the help given to them in the publication of the journal. British and American sources predominate in the first issue. Future numbers will be awaited with interest. The journal should do much, not only to bring Italian medical men the latest information on a wide variety of subjects, but also to promote co-operation between them and medical men in other countries.

\section{Trees Used for Animal Fodder in India}

Indian Forest Leaflet No. 82 (Sylviculture) (Forest Research Institute, Dehra Dun. Pp. iv +17. 8 an.) discusses those trees the foliage of which is used for animal fodder in India. It is the third edition of a small publication written by M. V. Laurie, then sylviculturist at the Forest Research Institute, Dehra Dun, first issued in 1939. It was quickly sold out, as also was the second edition, the present being a revised third edition. India has been one of the countries the population of which has been much addicted to tree lopping, usually to provide forage for animals. With the appearance of the Animal Husbandry Wing of the Agricultural Research Council in India, a start was made in collecting information on the subject of fodder grasses and general fodder supplies. It was left to the Forest Research Institute at Dehra Dun to institute inquiries into the trees used for this purpose-and used very often to the detriment of the forests so maltreated. The list does not make any claim to scientific accuracy, but merely represents the consolidated opinions of forest officers throughout India of the relative popularity of different trees for lopping for fodder.

\section{British Council Scholarships, 1946-47}

For the current academic year, 248 graduates and others of like status from overseas have been awarded British Council scholarships, which enable them to take a wide range of post-graduate courses of study in British universities and similar institutions. The scholarships are normally for one year, but extensions are granted in suitable cases. In addition, the Council has helped to place many students who have come to Britain under the auspices of overseas authorities or privately. The Council has this year established a Students' Welfare Department to deal with the reception and non-academic welfare of scholarship holders, and to help them to gain a general knowledge of British life and institutions. To this end vacation courses, which enable those residing in London to visit the provinces and vice-versa, as well as term-time talks, discussions, shows of documentary films and other events are arranged. These facilities are available also to students sponsored by the Colonial Office, the Indian and Sudan Governments, and to other overseas students. Scholarship holders this year have come from some fifty Empire and foreign countries. The awards are for various subjects, including agriculture and agricultural sciences (6), engineering and mining (15), sciences and technology (50).

\section{Spectrochimica Acta}

AN international medium for the publication of research results in applied spectroscopy was launched in 1939, and published by Julius Springer in Berlin until 1944. This is being revived under the joint editorship of several spectroscopists, as before. The editorial board will consist of: Dr. A. Gatterer (Vatican Observatory), Mr. E. van Someren (London), Prof. R. Breckpot (Louvain), Dr. W. Gerlach (Munich), Dr. H. Kaiser (Jena) and Dr. L. W. Strock (Saratoga Springs). The first number of the third volume should appear early in 1947, and authors of papers on emission or absorption spectroscopy are invited to submit manuscripts, in English, French, German or Italian, to the nearest member of the editorial board. Publication should be fairly prompt, by current standards. As in most scientific publications, authors are urged to be concise; but the paper supplies are sufficient to allow each author 75 reprints. The printing will be undertaken by the printers in the Vatican City, who are accustomed to dealing with a variety of languages. Authors in Great Britain should communicate with Mr. E. van Someren, 20 Churchfields, Broxbourne, Herts.

\section{Announcements}

The Medical Research Council has appointed Dr. S. T. Cowan (formerly of the University of Manchester) to succeed Dr. R. St. John Brooks as director of the National Collection of Type Cultures of Microorganisms. The Collection continues to be housed at the Elstree establishment of the Lister Institute of Preventive Medicine, but will be moved to the Central Public Health Laboratory at Colindale as soon as accommodation there is available.

Mr. J. B. BenNetT has been appointed to succeed the late Mr. W. Barnicot as secretary of Rothamsted Experimental Station.

IN accordance with its usual practice, Trinity College, Cambridge, announces the offer of a research studentship open to graduates of other universities who propose to go to Cambridge in October next as candidates for the degree of Ph.D. The value of the studentship may be as much as $£ 300$ a year. Candidates must not have reached the age of twenty-six before May 1 (length of war service can be added). The College also offers, as usual, exhibitions of the value of $£ 40$ to students of Dominion and Colonial universities who wish to go to Cambridge next October as candidates for the degree of B.A., M.Litt., M.Sc., or Ph.D. A candidate for a studentship or exhibition should apply through the principal authority of his university, and his application must reach the Senior Tutor, Trinity College, Cambridge (from whom further particulars may be obtained), by May 1. 